\title{
ACUMULAÇÃO DE BIOMASSA, CARACTERÍSTICAS FISIOLÓGICAS E RENDIMENTO DE GRÃOS EM CULTIVARES DE FEIJOEIRO IRRIGADO E SOB SEQUEIRO'
}

\author{
ARÃO ARAÚJO GOMES², ADELSON PAULO ARAÚJO, \\ ROBERTO OSCAR PEREYRA ROSSIELLO ${ }^{3}$ e CARLOS PIMENTEL ${ }^{4}$
}

\begin{abstract}
RESUMO - Em experimento de campo, foram avaliados o crescimento vegetativo e o rendimento de grãos de quatro cultivares de feijoeiro (Phaseolus vulgaris L.), sob condições de irrigação ou de sequeiro, correspondendo respectivamente a lâminas totais de água de 252 e $123 \mathrm{~mm}$. Foram efetuadas amostragens semanais da área foliar e da biomassa da parte aérea e seus componentes. Sob estresse hídrico, a biomassa da parte aérea, o índice de área foliar e a taxa de crescimento da cultura foram reduzidos em todas as cultivares. Não houve diferença significativa no rendimento de grãos sob sequeiro entre cultivares, mas sob deficiência hídrica o rendimento das cultivares foi reduzido, com exceção da 'Negro-Argel'. O número de vagens por planta foi o componente de produção mais afetado pelo regime de irrigação. Sob estresse hídrico, verificaram-se menores reduções na biomassa de ramos ao final do ciclo de 'Negro-Argel', na duração da área foliar e no rendimento de grãos, indicativos de maior tolerância à seca, enquanto na cultivar Carioca observou-se maior sensibilidade ao estresse hídrico.
\end{abstract}

Termos para indexação: Phaseolus vulgaris, genótipo, área foliar, matéria seca, taxa de crescimento, estresse hídrico.

\author{
ACCUMULATION OF BIOMASS, PHYSIOLOGICAL CHARACTERISTICS \\ AND GRAIN YIELD OF BEAN CULTIVARS UNDER IRRIGATED AND DRY REGIMES
}

\begin{abstract}
In a field experiment, the vegetative growth and the grain yield of four common bean (Phaseolus vulgaris L.) cultivars were evaluated under irrigated or rainfed conditions, corresponding to total water levels of 252 and $123 \mathrm{~mm}$, respectively. Leaf area and shoot biomass were weekly measured. The water stress reduced the shoot biomass, the leaf area index and the crop growth rate of all cultivars. There was no significant difference between cultivars in grain yield under rainfed; however, the water stress reduced grain yield in cultivars, except for Negro Argel. The number of pods per plant was the yield component most affected by the irrigation regimes. Under rainfed, 'Negro Argel' presented lower reductions in stem biomass at the end of growth cycle, in leaf area duration, and in grain yield, demonstrating a higher drought tolerance, whereas Carioca was the cultivar most sensitive to water stress.
\end{abstract}

Index terms: Phaseolus vulgaris, genotype, leaf area, dry matter, growth rate, water stress.

\footnotetext{
${ }^{1}$ Aceito para publicação em 7 de janeiro de 2000.

Extraído da dissertação de mestrado, apresentada pelo primeiro autor à Universidade Federal Rural do Rio de Janeiro (UFRRJ), Seropédica, RJ.

${ }^{2}$ Lic. Ciências Agrícolas, M.Sc., Doutorando, Dep. de Fitotecnia, UFRRJ, CEP 23890-000 Seropédica, RJ.

E-mail: aaron@ufrrj.br

${ }^{3}$ Eng. Agrôn., Ph.D., Dep. de Solos, UFRRJ.

E-mail: aparaujo@ufrrj.br,ropr@ufrrj.br

${ }^{4}$ Eng. Agrôn., Ph.D., Dep. de Fitotecnia, UFRRJ.

E-mail: greenman@amcham.com.br
}

\section{INTRODUÇÃO}

Nos países menos desenvolvidos, o feijoeiro (Phaseolus vulgaris L.) é cultivado sobretudo por pequenos e médios produtores, sem o uso de irrigação, e, por isso, em mais de $60 \%$ do seu cultivo observa-se deficiência hídrica em algum estádio da cultura (Singh, 1995). O requerimento hídrico do feijoeiro é variável, sendo influenciado por fatores como época e local de semeadura, variedade, condições 
edafoclimáticas e estádio de desenvolvimento (Moreira et al., 1996). A quantidade de água requerida pela cultura, para obtenção de máxima produtividade, varia entre 300 e 500 mm (Doorenbos \& Kassam, 1979), mas têm sido relatados consumos inferiores (Loureiro et al., 1990).

O feijoeiro é considerado uma planta sensível ao estresse hídrico, principalmente em virtude da baixa capacidade de recuperação após a deficiência hídrica e sistema radicular pouco desenvolvido (Guimarães, 1996). A fase da planta mais sensível à deficiência de água é a reprodutiva, sendo altamente vulnerável desde o início da floração até o início da formação das vagens (Fageria et al., 1991). A produtividade é mais afetada quando o estresse hídrico ocorre aos 5 a 10 dias antes da antese, podendo haver uma diminuição superior a $50 \%$ no rendimento (Norman et al., 1995). Esse efeito é causado principalmente pela baixa taxa de polinização e pelo aborto de óvulos, que causam abscisão dos órgãos reprodutivos, resultante do decréscimo na translocação de fotoassimilados das folhas para as flores (Kramer \& Boyer, 1995).

A obtenção de cultivares de feijoeiro com alta produtividade e menor demanda por insumos vem sendo o objetivo de vários estudos. A pesquisa sobre adaptação do feijoeiro à seca envolve estudos sobre os efeitos da falta de água e os mecanismos de adaptação, determinação dos caracteres fisiológicos indicadores de tolerância, desenvolvimento de técnicas de seleção de germoplasma e identificação de fontes de tolerância (Singh, 1995).

Este trabalho teve por objetivo avaliar a distribuição de matéria seca na parte aérea de quatro cultivares de feijoeiro, sob condições de sequeiro ou irrigação, e suas relações com o rendimento de grãos, por meio de técnicas de análise de crescimento vegetal.

\section{MATERIAL E MÉTODOS}

O trabalho foi desenvolvido no campo experimental do Departamento de Fitotecnia da Universidade Federal Rural do Rio de Janeiro (UFRRJ), em solo Podzólico Vermelho-Amarelo, série Silvicultura, cuja camada superficial $(0-20 \mathrm{~cm})$ apresentou: textura franco-argilo-arenosa, capacidade de campo $134 \mathrm{~g} \mathrm{~kg}^{-1}$, ponto de murchamento $90 \mathrm{~g} \mathrm{~kg}^{-1}$, pH em água 6,4, 19,8 $\mathrm{g} \mathrm{kg}^{-1} \mathrm{de} \mathrm{C}, 45 \mathrm{mmol}_{\mathrm{c}} \mathrm{dm}^{-3}$ de Ca, 8 mmol $_{\mathrm{c}} \mathrm{dm}^{-3}$ de $\mathrm{Mg}, 4 \mathrm{mmol}_{\mathrm{c}} \mathrm{dm}^{-3} \mathrm{de} \mathrm{Al}, 97 \mu \mathrm{g} \mathrm{g}^{-1}$ de $\mathrm{K}, 3,0 \mu \mathrm{g} \mathrm{g} \mathrm{g}^{-1} \mathrm{de}$ P. O preparo do solo consistiu de aração e gradagem, e foram aplicados $500 \mathrm{~kg} \mathrm{ha}^{-1}$ de calcário. A adubação mineral constou da aplicação de $40 \mathrm{~kg} \mathrm{ha}^{-1} \mathrm{de} \mathrm{N}$, $44 \mathrm{~kg} \mathrm{ha}^{-1}$ de $\mathrm{P}$ e $50 \mathrm{~kg} \mathrm{ha}^{-1}$ de $\mathrm{K}$, nas formas de uréia, superfosfato simples e cloreto de potássio, respectivamente; aos 30 dias após a semeadura (DAS) foram aplicados $20 \mathrm{~kg} \mathrm{ha}^{-1}$ de $\mathrm{N}$ em cobertura, como uréia. Foram distribuídas dez sementes por metro, infectadas com Rhizobium leguminosarum biovar phaseoli.

$\mathrm{O}$ experimento apresentou esquema fatorial $2 \times 4$, em delineamento em blocos ao acaso, com parcelas subdivididas e três repetições; as parcelas correspondiam aos tratamentos irrigado e não-irrigado, e as subparcelas, às cultivares. Cada subparcela era constituída de cinco linhas de $5 \mathrm{~m}$ de comprimento e espaçamento de $0,5 \mathrm{~m}$. Foram estudadas as cultivares: Xodó, de hábito de crescimento de tipo II, sementes opacas-preto-manchadas; Carioca, de tipo III, com sementes de cor bege-rajadas; Negro Argel, de tipo III, com sementes pretas-opacas; A320, linhagem ainda não estabelecida como cultivar, de tipo III, com sementes de cor bege.

Foi avaliada a umidade do solo a cada dois dias, por meio do método gravimétrico. A lâmina de irrigação foi calculada de forma a elevar-se a umidade do solo à capacidade de campo, na profundidade de $0,2 \mathrm{~m}$, quando a tensão de água no solo era menor que - $0,03 \mathrm{MPa}$, o que levou a um turno de rega entre dois e três dias. A quantidade de água em cada subparcela foi distribuída com mangueira.

Ao longo do ciclo da cultura foram efetuadas amostragens de biomassa em cada subparcela, iniciadas aos 14 DAS e espaçadas de sete dias umas das outras. Em cada coleta, duas plantas por subparcela foram cortadas rente ao solo e separadas em ramos, folhas e vagens. A área foliar foi estimada por um medidor fotoelétrico (LI-3000, Li-Cor), e cada parte da planta foi secada em estufa e pesada. Durante maturação dos grãos, aos 98 DAS, foram colhidas as três linhas centrais de cada subparcela, avaliando-se o número de plantas, número de vagens, número de grãos e rendimento de grãos.

Os dados de massa seca e área foliar foram convertidos para biomassa por área de terreno e índice de área foliar (IAF), considerando a densidade final de plantas de cada parcela. A homogeneidade das variâncias entre os dados de distintas coletas foi verificada pelo teste de Hartley (Neter et al., 1990), procedendo-se a transformação dos dados em logaritmo natural. Efetuou-se análise de variância iso- 
ladamente para cada cultivar e avaliaram-se os efeitos de irrigação, coleta e sua interação, considerando as coletas como subparcelas. Para o rendimento de grãos e componentes de produção, foram avaliados efeitos de irrigação, cultivar (como subparcela) e sua interação.

Entre as funções testadas para ajuste dos dados ao longo do tempo, foram escolhidos os modelos exponencial polinomial do 2 o grau para a biomassa da parte aérea, e do 3o grau para o índice de área foliar. A partir dessas funções, foram derivadas as taxas de crescimento da cultura (TCC) e de assimilação líquida (TAL) (Hunt, 1982). A duração da área foliar, correspondente à área inferior à curva de IAF (Hunt, 1982), foi calculada pelo somatório das médias de dois valores diários consecutivos de IAF, estimados pelas funções ajustadas.

\section{RESULTADOS E DISCUSSÃO}

Durante o período experimental, com semeadura em 5 de maio de 1992, foram registradas as seguintes condições ambientais: temperatura média de $22,0 \pm 0,2^{\circ} \mathrm{C}$, umidade relativa de $65,8 \pm 1,0 \%$, evaporação (tanque classe A) de $3,3 \pm 0,2 \mathrm{~mm}$, e lâmina total de irrigação de 123 e $252 \mathrm{~mm}$, respectivamente nos tratamentos sob sequeiro e irrigação. As maiores taxas de evaporação foram observadas entre os $30 \mathrm{e}$ 40 DAS, período em que também verificaram-se os menores valores de umidade relativa do ar. Segundo Moreira et al. (1996), uma cultura do feijão, com preparo do solo convencional, necessitou de uma lâmina total de irrigação de $536 \mathrm{~mm}$ para obtenção de produtividade acima de $2.000 \mathrm{~kg} \mathrm{ha}^{-1}$, ao passo que sob plantio direto foram necessários $382 \mathrm{~mm}$. A economia de água verificada neste sistema é resultado da redução na evaporação de água do solo. Nas condições experimentais da UFRRJ, a lâmina total de irrigação, no tratamento irrigado $(252 \mathrm{~mm})$, foi mais baixa que esses valores, provavelmente por causa da alta umidade relativa do ar, podendo ter ocorrido alguma deficiência hídrica, pouco severa, durante o ciclo das plantas irrigadas.

Em ambos os sistemas de cultivo, sob irrigação ou sequeiro, observaram-se três estádios de crescimento do feijoeiro: uma fase inicial, de crescimento relativamente lento, uma intermediária, dos 35 aos 63-70 DAS, em que o crescimento foi acelerado, sobretudo no tratamento irrigado, e a fase final, em que teve decréscimo acentuado, em decorrência da senescência foliar (Fig. 1). A floração plena ocorreu entre 36 e 39 DAS em todas as cultivares, e o início da formação das vagens deu-se entre 40 e 44 DAS. Como o ciclo das cultivares diferiu, foram efetuadas 10 coletas da Carioca e Negro Argel, 11 coletas da A320, e 12 coletas da Xodó. Sob estresse hídrico, o acúmulo de massa seca nos ramos, folhas e parte aérea foi severamente reduzido em todas as cultivares, a partir dos 28-35 DAS, ou seja, as limitações no crescimento em resposta à menor disponibilidade hídrica foram identificadas já na fase vegetativa (Fig. 1 e Tabela 1), conforme assinalado por Guimarães (1996).

Sob sequeiro, observou-se, na cultivar Carioca, uma redução mais acentuada na biomassa de parte aérea do que nas demais (Fig. 1), indicando maior sensibilidade ao estresse hídrico. Nessa condição, o acúmulo máximo de biomassa da parte aérea, nas cultivares Carioca e Xodó, foi antecipado em sete dias em comparação ao tratamento irrigado; já em A320, o acúmulo máximo foi coincidente em ambos os tratamentos (Fig. 1). Comportamento diferente foi observado na cultivar Negro Argel, em que o acúmulo máximo de matéria seca sob estresse hídrico foi retardado, ocorrendo somente ao final do ciclo (Fig. 1). Portanto, foi observada uma variabilidade genética no acúmulo da biomassa máxima do feijoeiro, sob deficiência hídrica (Guimarães, 1996).

Em todas as cultivares, a acumulação máxima de biomassa nas folhas ocorreu entre 56 e 63 DAS, nos ramos, entre 63 e 70 DAS, e nas vagens, entre 70 e 77 DAS, nos dois tratamentos (Tabela 1), ou seja, a acumulação preferencial de massa seca ocorreu nas folhas, depois nos ramos e finalmente nas vagens, corroborando Costa et al. (1991). Em leguminosas, os fotoassimilados, produzidos pelas folhas, são acumulados intermediariamente nos ramos, sendo posteriormente translocados para as vagens (Subbarao et al., 1995). O acúmulo máximo de biomassa nos ramos, em 'Negro Argel', ocorreu aos 63 DAS, no regime irrigado, e aos 70 DAS, sob sequeiro (Tabela 1).

A redução de massa de folhas secas, a partir de um máximo aos 63 DAS até a última coleta, foi semelhante em plantas irrigadas ou não, sendo em média 

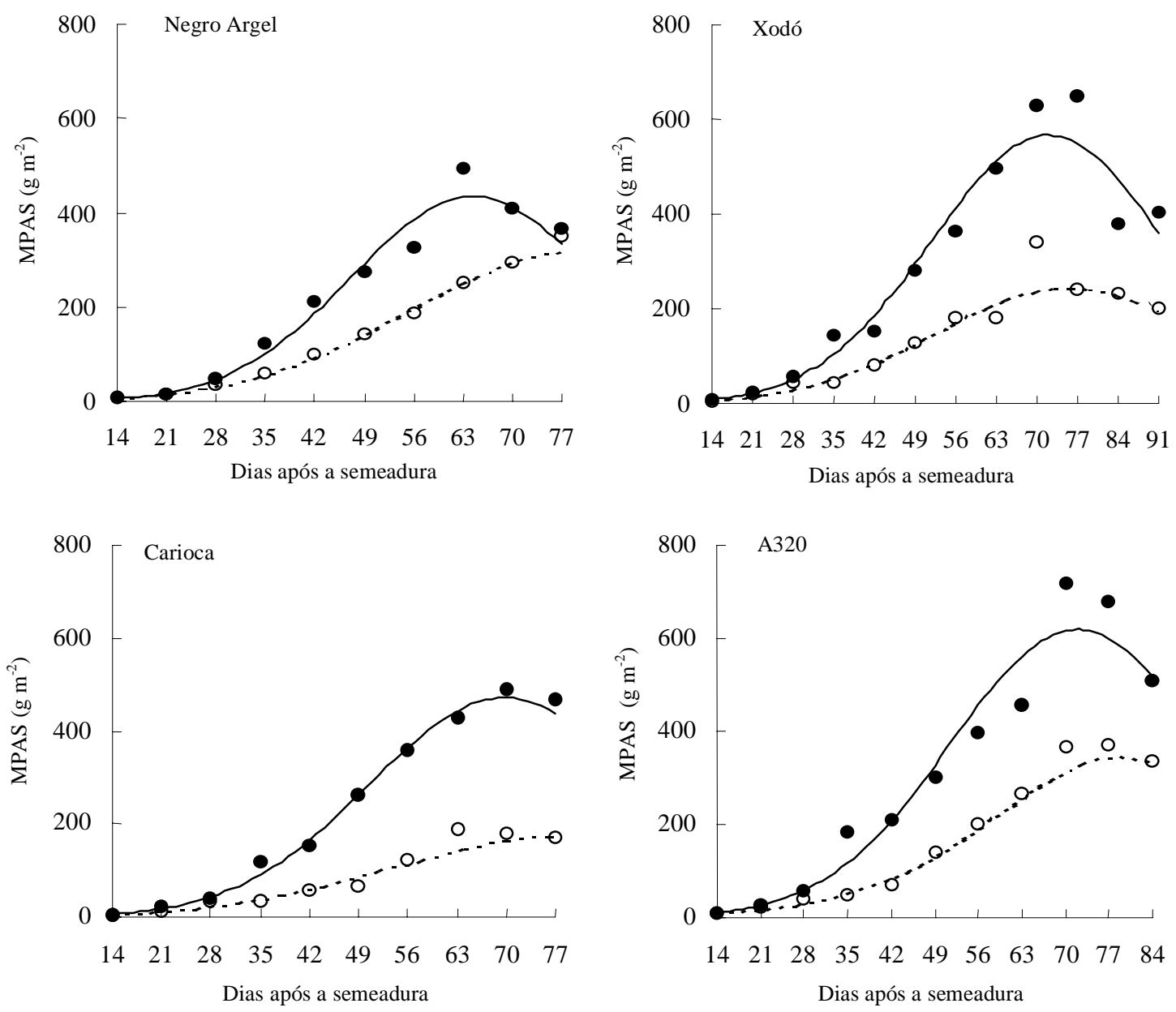

FIG. 1. Massa de parte aérea seca (MPAS) de quatro cultivares de feijoeiro, em diferentes épocas de coleta, sob dois regimes de irrigação. Linha tracejada: não-irrigado; linha cheia: irrigado; os pontos referem-se às médias experimentais $\left(r^{2}>0,93\right)$.

de $62 \%$ na 'Negro Argel', $71 \%$ na 'Xodó', $45 \%$ na 'Carioca' e de 50\% na 'A320' (Tabela 1). Já a redução na massa de ramos secos, entre 70 DAS e a última coleta, foi menor nas plantas sob estresse hídrico: na cultivar Negro Argel foi de $24 \%$ em plantas estressadas e de $52 \%$ nas irrigadas; na Xodó, de $39 \%$ e $52 \%$; na Carioca, de $43 \%$ e $36 \%$, e na A 320 , de $26 \%$ e $30 \%$, respectivamente (Tabela 1 ).

Em 'Negro-Argel' e 'A320' observaram-se as maiores produções de massa de vagens secas sob sequeiro (Tabela 1). Sob estresse hídrico, foi reduzida a massa das vagens secas, incluindo-se as se- mentes em formação (Tabela 1), provavelmente em resposta à menor produção de fotoassimilados (Kramer \& Boyer, 1995). Nas cultivares Negro Argel e Carioca, de ciclos mais curtos, houve aumento contínuo na produção de massa seca de vagens; já na 'Xodó' e ‘A320' observou-se redução após 77 DAS, indicando abscisão de vagens (Tabela 1).

O cume na taxa de crescimento da cultura (TCC) ocorreu aproximadamente aos 49 e 56 DAS nos tratamentos irrigado e não-irrigado, respectivamente (Fig. 2). Sob estresse hídrico, a TCC foi reduzida em todas as cultivares, mas de forma mais intensa na 
TABELA 1. Massa de folhas, ramos e vagens secos, e duração da área foliar de quatro cultivares de feijoeiro em diferentes épocas de coleta, sob dois regimes de irrigação ${ }^{1}$.

\begin{tabular}{|c|c|c|c|c|c|c|c|c|}
\hline \multirow{2}{*}{$\begin{array}{l}\text { Dias após a } \\
\text { semeadura }\end{array}$} & \multicolumn{2}{|c|}{ Negro Argel } & \multicolumn{2}{|c|}{ Xodó } & \multicolumn{2}{|c|}{ Carioca } & \multicolumn{2}{|c|}{ A 320} \\
\hline & Não-irrigado & Irrigado & Não-irrigado & Irrigado & Não-irrigado & Irrigado & Não-irrigado & Irrigado \\
\hline & \multicolumn{8}{|c|}{ Massa de folhas secas $\left(\mathrm{g} \mathrm{m}^{-2}\right)$} \\
\hline 14 & 5,3 & 5,2 & 4,3 & 5,9 & 4,0 & 5,0 & 6,9 & 7,2 \\
\hline 21 & 13,0 & 11,6 & 14,1 & 17,8 & 11,1 & 16,7 & 15,5 & 20,2 \\
\hline 28 & 24,4 & $35,3^{*}$ & 30,1 & 39,9 & 23,3 & 28,3 & 25,9 & $42,1 *$ \\
\hline 35 & 37,9 & $81,6^{*}$ & 26,8 & $92,5^{*}$ & 22,4 & $78,8 *$ & 30,2 & $121,0 *$ \\
\hline 42 & 62,7 & $133,3 *$ & 47,5 & $91,2 *$ & 35,5 & $95,1 *$ & 44,0 & $128,5^{*}$ \\
\hline 49 & 78,8 & $151,8 *$ & 69,5 & $148,5^{*}$ & 36,4 & $135,2 *$ & 75,8 & $165,3^{*}$ \\
\hline 56 & 81,1 & $153,2 *$ & 78,0 & $163,7^{*}$ & 54,3 & $153,2 *$ & 90,8 & $177,7^{*}$ \\
\hline 63 & 90,3 & $167,8 *$ & 61,5 & $185,6^{*}$ & 60,3 & $128,4^{*}$ & 102,2 & $178,0 *$ \\
\hline 70 & 81,9 & $125,8^{*}$ & 75,0 & $163,4^{*}$ & 56,7 & $117,2 *$ & 85,8 & $177,4 *$ \\
\hline 77 & 35,4 & $59,7 *$ & 43,6 & $132,1^{*}$ & 34,8 & $77,5^{*}$ & 63,4 & $153,4^{*}$ \\
\hline 84 & & & 28,8 & $60,3^{*}$ & & & 49,8 & $90,1 *$ \\
\hline \multirow[t]{2}{*}{91} & & & 21,5 & $56,1 *$ & & & & \\
\hline & \multicolumn{8}{|c|}{ Massa de ramos secos $\left(\mathrm{g} \mathrm{m}^{-2}\right)$} \\
\hline 14 & 1,6 & 1,5 & 1,5 & 1,8 & 1,3 & 1,4 & 2,3 & 2,3 \\
\hline 21 & 4,8 & 3,6 & 5,2 & 6,0 & 4,0 & 5,3 & 5,7 & 6,1 \\
\hline 28 & 9,6 & 13,5 & 14,0 & 16,7 & 10,1 & 11,6 & 12,0 & $16,5^{*}$ \\
\hline 35 & 20,4 & $41,0 *$ & 14,9 & $51,6^{*}$ & 11,5 & $39,5^{*}$ & 15,4 & $61,0^{*}$ \\
\hline 42 & 34,6 & $75,0 *$ & 30,2 & $59,4 *$ & 19,2 & $55,9 *$ & 24,4 & $76,8^{*}$ \\
\hline 49 & 53,1 & $114,3^{*}$ & 49,4 & $121,6^{*}$ & 24,5 & $110,2 *$ & 49,6 & $122,2 *$ \\
\hline 56 & 59,3 & $107,6 *$ & 56,1 & $137,2^{*}$ & 35,8 & $133,6^{*}$ & 59,8 & $136,6^{*}$ \\
\hline 63 & 63,4 & $166,1 *$ & 52,1 & $181,9 *$ & 51,6 & $125,6^{*}$ & 68,6 & $128,6^{*}$ \\
\hline 70 & 74,0 & 102,1 & 70,0 & $187,3^{*}$ & 43,8 & $101,6^{*}$ & 70,5 & $142,8 *$ \\
\hline 77 & 56,5 & $79,5^{*}$ & 48,1 & $138,6^{*}$ & 29,3 & $85,0^{*}$ & 62,6 & $122,8^{*}$ \\
\hline 84 & & & 50,8 & $84,9 *$ & & & 52,3 & $99,5^{*}$ \\
\hline \multirow[t]{2}{*}{91} & & & 42,8 & $90,5^{*}$ & & & & \\
\hline & \multicolumn{8}{|c|}{ Massa de vagens secas $\left(\mathrm{g} \mathrm{m}^{-2}\right)$} \\
\hline 49 & 9,1 & 6,2 & 8,9 & 7,7 & 4,4 & 12,0 & 14,4 & 9,4 \\
\hline 56 & 45,8 & 63,6 & 46,4 & 61,6 & 31,7 & 67,7 & 49,5 & 81,4 \\
\hline 63 & 95,7 & 158,3 & 64,9 & $127,6^{*}$ & 74,6 & 175,0 & 94,0 & 149,4 \\
\hline 70 & 139,2 & 182,3 & 195,0 & 277,0 & 76,7 & 272,7 & 210,5 & 398,1 \\
\hline 77 & 257,1 & 225,9 & 149,3 & $376,5^{*}$ & 106,7 & 307,0 & 242,8 & 401,2 \\
\hline 84 & & & 152,8 & $234,1^{*}$ & & & 232,4 & 318,3 \\
\hline \multirow[t]{2}{*}{91} & & & 134,6 & $258,1^{*}$ & & & & \\
\hline & \multicolumn{8}{|c|}{ Duração da área foliar (dias) $)^{2}$} \\
\hline Ciclo total & 123 & 207 & 103 & 206 & 70 & 182 & 124 & 294 \\
\hline \multicolumn{9}{|c|}{$\begin{array}{l}\text { 1. Dados originais transformados em logaritmo natural antes da análise } \\
2 \text { Não foi feita análise estatística dos dados de duração de área foliar. } \\
\text { * Diferença significativa entre regimes de irrigação (teste F a 5\%), calc }\end{array}$} \\
\hline \multicolumn{9}{|c|}{$\begin{array}{ll}\text { Carioca, com TCC máxima em torno de } 4 \mathrm{e} 15 \mathrm{~g} \mathrm{~m}^{-2} \mathrm{dia}^{-1}, & \text { tensão de água no solo, a TCC do feijoeiro é reduzi- } \\
\text { respectivamente sob sequeiro e com irrigação (Fig. 2). } & \text { da (Stone et al., 1988), o que é atribuído à redução na } \\
\text { Entretanto, em todas as cultivares os decréscimos } & \text { condutância estomática, promovendo não só dimi- } \\
\text { na TCC, ao final do ciclo, foram mais intensos sob } & \text { nuição na taxa transpiratória como também da entra- } \\
\text { irrigação (Fig. 2), indicando uma maior translocação } & \text { da de } \mathrm{CO}_{2}, \text { e conseqüente diminuição da fotossíntese } \\
\text { de fotossintatos em relação aos grãos. Sob elevada } & \text { (Subbarao et al., 1995). }\end{array}$} \\
\hline
\end{tabular}



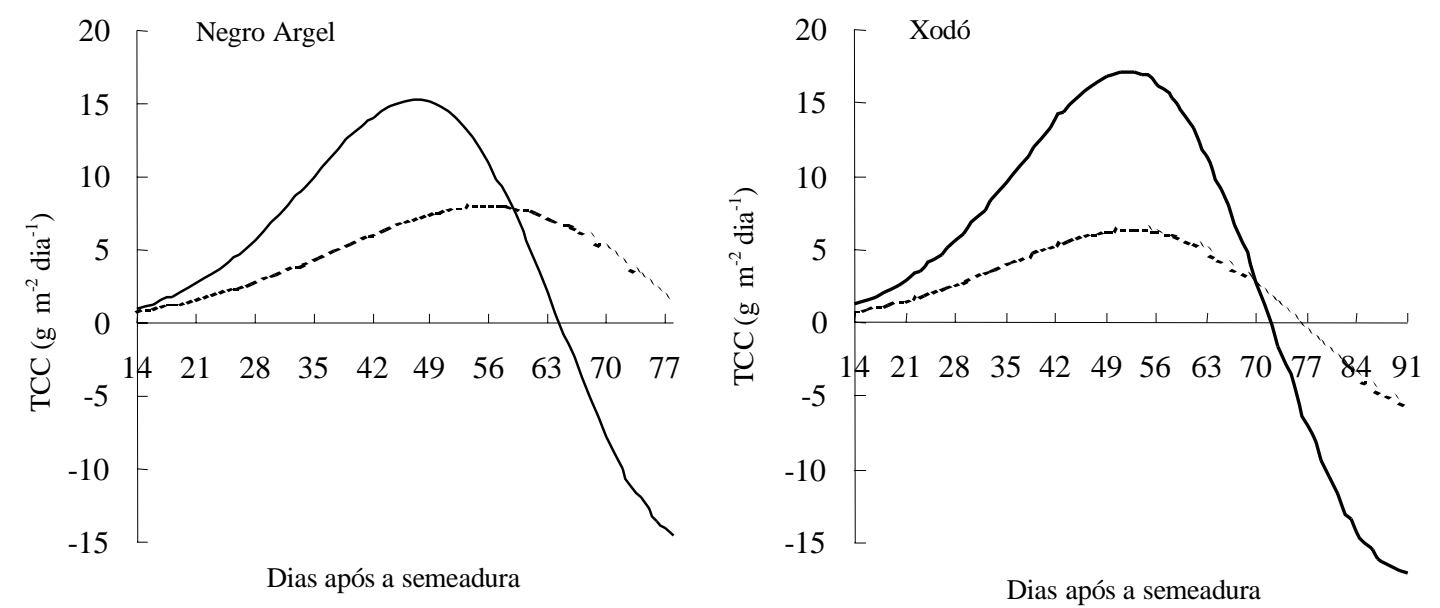

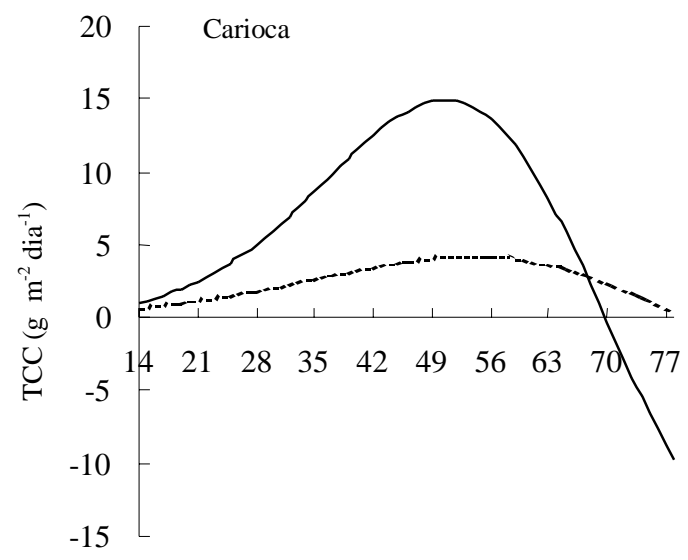

Dias após a semeadura

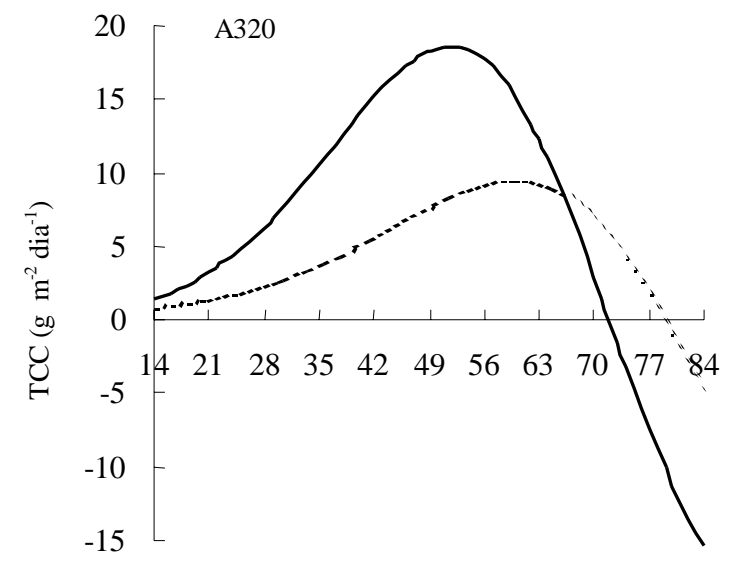

Dias após a semeadura

FIG. 2. Taxa de crescimento da cultura (TCC) de quatro cultivares de feijoeiro sob dois regimes de irrigação. Linha tracejada: não-irrigado; linha cheia: irrigado.

Em ambos os regimes de irrigação, e para todas as cultivares, os valores de índice de área foliar (IAF) foram crescentes até aproximadamente os 63 DAS, com decréscimo acentuado a partir desta; já em 'Carioca', o IAF máximo foi obtido aos 56 DAS (Fig. 3). Os maiores valores de IAF foram observados nas cultivares Negro Argel e A320, em ambos os tratamentos (Fig. 3). O IAF e a massa dos folíolos secos foram muito reduzidos sob estresse hídrico, já a partir dos 28-35 DAS (Fig. 3 e Tabela 1), com diminuição em tamanho e principalmente em número, como verificado por Brandes et al. (1973) e Costa et al. (1991).
Bascur et al. (1985) observaram valores próximos de 6 para o IAF de cultivares de feijoeiro, sob irrigação, comparado com o valor 4 , sob estresse hídrico.

Sob estresse hídrico, os maiores valores de duração da área foliar foram observados em 'Negro Argel' e ‘A320', e a maior redução da duração da área foliar foi na cultivar Carioca, em comparação ao tratamento irrigado (Tabela 1). A maior duração da área foliar em condições de sequeiro é vantajosa, pois a senescência foliar no período de enchimento das vagens é uma das principais causas do aborto de vagens e conseqüente baixa produtividade do 

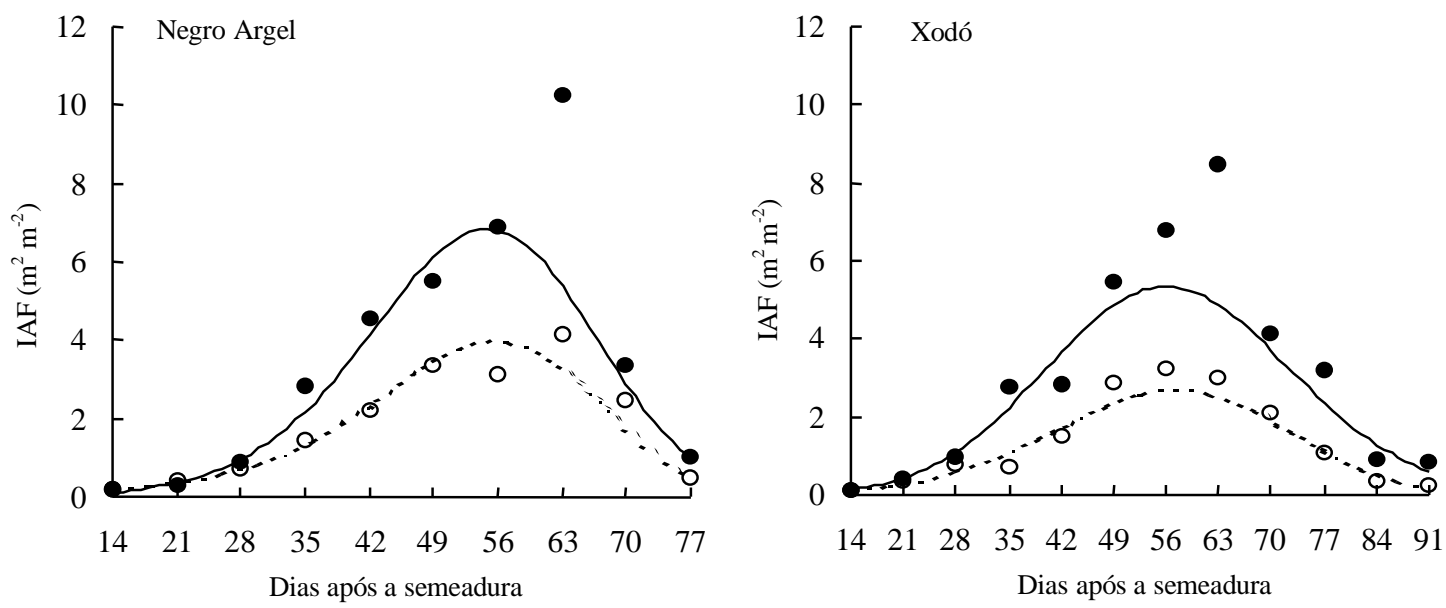

$\begin{array}{llllllllllll}14 & 21 & 28 & 35 & 42 & 49 & 56 & 63 & 70 & 77 & 84 & 91\end{array}$

Dias após a semeadura
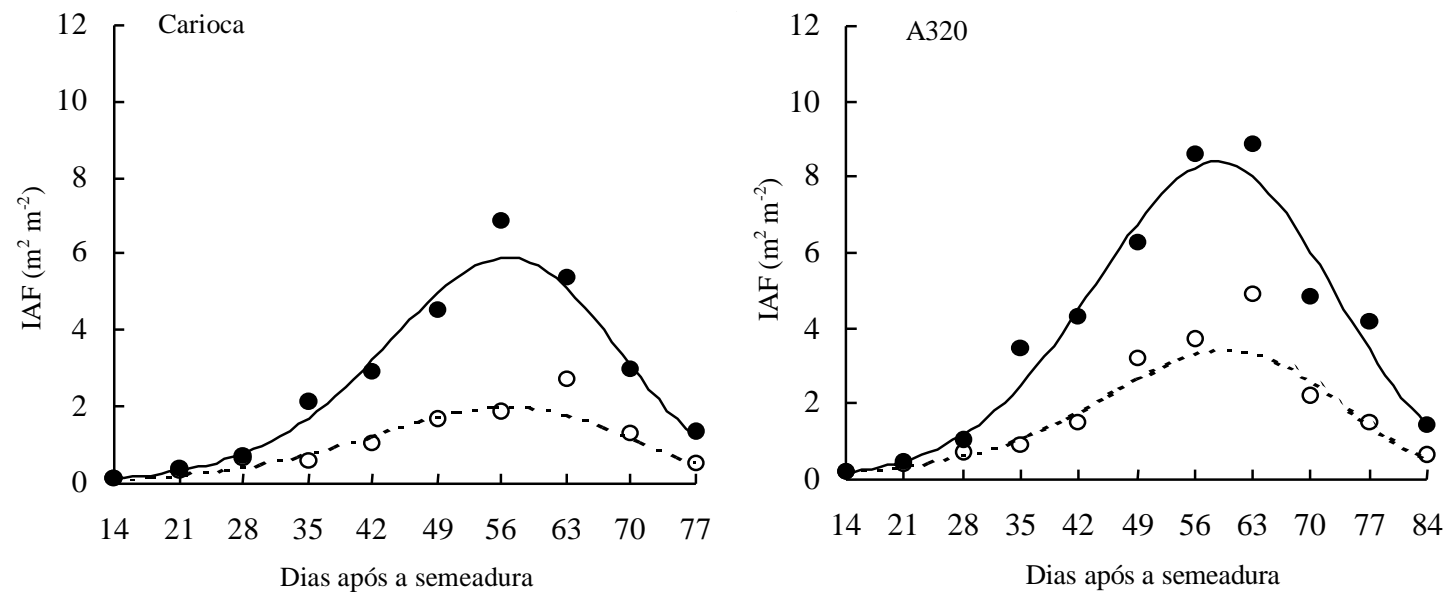

FIG. 3. Índice de área foliar (IAF) de quatro cultivares de feijoeiro, em diferentes épocas de coleta, sob dois regimes de irrigação. Linha tracejada: não-irrigado; linha cheia: irrigado; os pontos referem-se às médias experimentais $\left(\mathbf{r}^{2}>0,87\right)$.

feijoeiro sob estresse (Guimarães, 1996). A redução no IAF e na duração da área foliar sob sequeiro (Fig. 3 e Tabela 1) pode ser utilizada como parâmetro indicador do efeito do estresse hídrico no feijoeiro (Blum, 1997), sendo a duração da área foliar uma característica a ser obtida em estudos de melhoramento vegetal para tolerância à seca na espécie (Stone et al., 1988; Subbarao et al., 1995).

Os maiores valores da taxa de assimilação líquida (TAL) ocorreram na fase vegetativa (Fig. 4). Em geral, há uma tendência para diminuição da TAL com a expansão foliar, principalmente em virtude do auto- sombreamento, podendo ser atingidos valores negativos em resposta à redução no acúmulo de biomassa ao final do ciclo (Hunt, 1982), o que foi observado nas cultivares, após os 70 DAS (Fig. 4). Apesar das dificuldades envolvidas na comparação estatística das estimativas da TAL (Hunt, 1982), verifica-se que sob deficiência hídrica houve redução da TAL, na fase de crescimento vegetativo, em todas as cultivares (Fig. 4). Considerando-se a TAL como estimativa da fotossíntese líquida, pode-se concluir que, sob estresse hídrico, a produção de biomassa foi reduzida, principalmente pela redução 


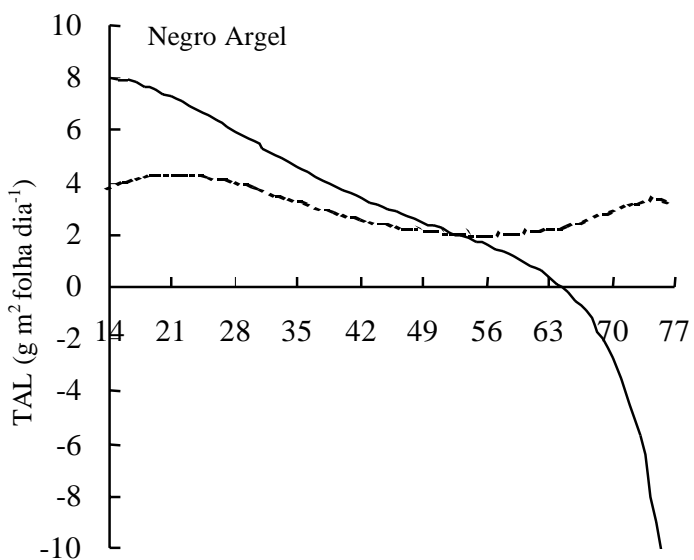

Dias após a semeadura

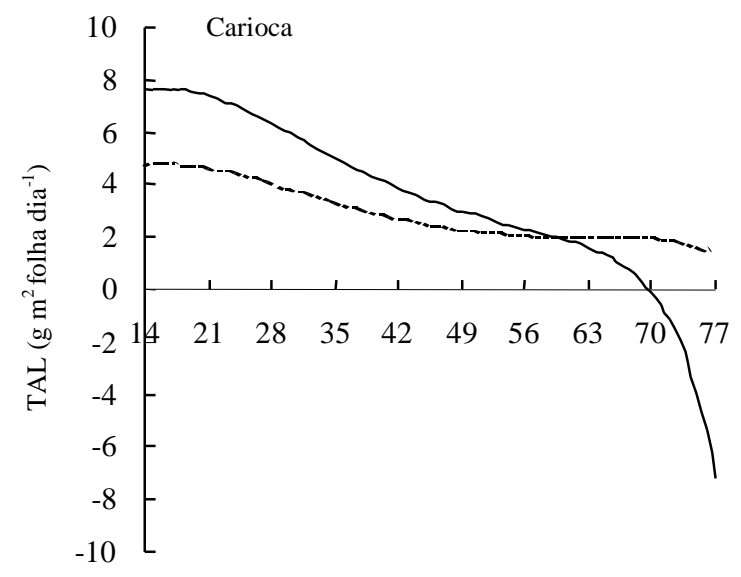

Dias após a semeadura

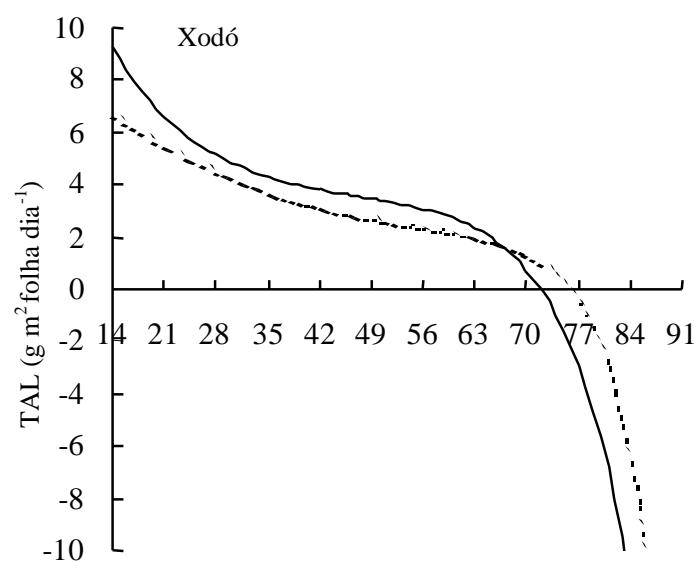

Dias após a semeadura

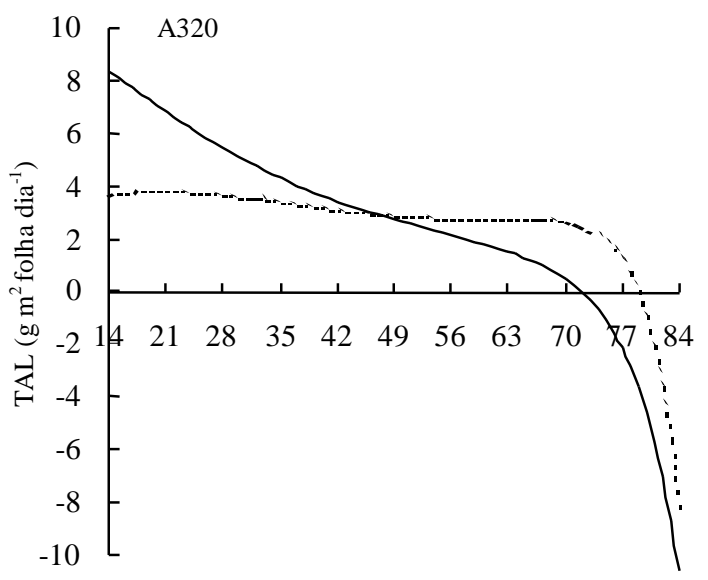

Dias após a semeadura

FIG. 4. Taxa de assimilação líquida (TAL) de quatro cultivares de feijoeiro, sob dois regimes de irrigação. Linha tracejada: não-irrigado; linha cheia: irrigado.

no IAF e, em menor intensidade, nas taxas fotossintéticas (Figs. 3 e 4), confirmando observações de Brandes et al. (1973) e Stone et al. (1988). Desta forma, a redução no crescimento, em resposta ao decréscimo da disponibilidade de água no solo, pode ser atribuída à diminuição da atividade fotossintética, pelo fechamento estomático (Kramer \& Boyer, 1995) e, sobretudo, pela redução da área foliar fotossinteticamente ativa (Neumann et al., 1997).

Não se detectou diferença significativa entre os valores de rendimento de grãos das cultivares, sob deficiência hídrica (Tabela 2). Essa similaridade de rendimento sob sequeiro reflete a dificuldade na identificação da tolerância à seca nos genótipos de feijoeiro cultivados no Brasil, talvez em virtude de sua base genética estreita e origem comum (Singh, 1995). Sob estresse hídrico, o rendimento de grãos nas cultivares Xodó, Carioca e A320 foi significativamente reduzido, mas não na cultivar Negro Argel (Tabela 2). O maior decréscimo do rendimento sob sequeiro foi observado na cultivar Carioca, com redução porcentual no rendimento e no número de vagens por planta ao redor de $60 \%$. Sob irrigação, des- 
TABELA 2. Rendimento de grãos e componentes da produção de quatro cultivares de feijoeiro, sob dois regimes de irrigação ${ }^{1}$.

\begin{tabular}{|c|c|c|c|c|c|c|c|c|c|c|c|c|}
\hline \multirow[t]{2}{*}{ Cultivar } & \multicolumn{3}{|c|}{$\begin{array}{l}\text { Rendimento de grãos } \\
\qquad\left(\mathrm{g} \mathrm{m}^{-2}\right)\end{array}$} & \multicolumn{3}{|c|}{$\begin{array}{l}\text { Número de vagens } \\
\text { por planta }\end{array}$} & \multicolumn{3}{|c|}{$\begin{array}{c}\text { Número de grãos } \\
\text { por vagem }\end{array}$} & \multicolumn{3}{|c|}{$\begin{array}{c}\text { Massa de } 100 \text { grãos } \\
(\mathrm{g})\end{array}$} \\
\hline & $\begin{array}{l}\text { Não- } \\
\text { irrigado }\end{array}$ & Irrigado & Média & $\begin{array}{l}\text { Não- } \\
\text { irrigado }\end{array}$ & Irrigado & Média & $\begin{array}{l}\text { Não- } \\
\text { irrigado }\end{array}$ & Irrigado & Média & $\begin{array}{l}\text { Não- } \\
\text { irrigado }\end{array}$ & Irrigado & Média \\
\hline Negro Argel & $91,2 \mathrm{a}$ & $109,2 b$ & $100,2 b$ & 8,6 & 9,6 & 9,1 & 3,7 & 4,4 & 4,1 & 22,4 & 20,8 & $21,6 b$ \\
\hline Xodó & $90,0 \mathrm{a}$ & $218,8 a^{*}$ & $154,4 \mathrm{ab}$ & 7,2 & 13,0 & 10,1 & 3,3 & 4,6 & 4,0 & 22,4 & 21,6 & $22,0 \mathrm{~b}$ \\
\hline Carioca & $64,1 \mathrm{a}$ & $165,5 \mathrm{ab}^{*}$ & $114,8 b$ & 4,5 & 10,6 & 7,6 & 4,0 & 4,9 & 4,5 & 22,0 & 19,9 & $21,0 \mathrm{~b}$ \\
\hline A 320 & $120,5 \mathrm{a}$ & $230,8 a^{*}$ & $175,7 \mathrm{a}$ & 6,2 & 10,3 & 8,3 & 3,7 & 4,6 & 4,2 & 26,5 & 25,5 & $26,0 \mathrm{a}$ \\
\hline Média & 91,5 & $181,1^{*}$ & & 6,6 & $10,9 *$ & & 3,7 & 4,7 & & 23,3 & 22,0 & \\
\hline
\end{tabular}

${ }^{1}$ Médias seguidas de mesma letra, na coluna, não diferem pelo teste de Tukey a $5 \%$ de probabilidade.

* Diferença significativa entre regimes de irrigação (teste F a 5\%).

tacam-se os valores de rendimento de 'Xodó' e 'A320', que só não foram estatisticamente diferentes da cultivar Carioca, e somente na cultivar Negro Argel o rendimento foi significativamente inferior aos valores dessas duas cultivares (Tabela 2). Nestas condições, 'Xodó' e ‘A320' apresentaram também os maiores valores de acúmulo de biomassa da parte aérea seca (Fig. 1).

Não houve diferenças significativas entre as cultivares quanto ao número de vagens por planta e ao número de grãos por vagem, mas, estatisticamente, a maior massa de 100 grãos foi observada na 'A320' (Tabela 2). Sob estresse hídrico, o número de vagens por planta foi reduzido em todas as cultivares (Tabela 2), pois esse componente de produção é o mais afetado pelo estresse hídrico severo (Guimarães et al., 1996). O decréscimo no rendimento sob sequeiro ocorre em razão de polinização deficiente ou da redução do número de flores estabelecidas, em virtude da abscisão floral ou do aborto dos óvulos (Kramer \& Boyer, 1995). Sob estresse hídrico, o número de grãos por vagem foi reduzido e a massa de 100 grãos foi aumentada, mas tais efeitos não foram estatisticamente significativos (Tabela 2). Loureiro et al. (1990) verificaram que o rendimento de grãos e o número de vagens por planta do feijoeiro podem ser modificados pelo regime de irrigação, mas não o número de grãos por vagem e a massa de 100 grãos.

Constable \& Hearn (1978), comparando duas cultivares de soja, mostraram que na menos produtiva, sob deficiência hídrica, a massa seca foi acumulada em ramos até a floração, decrescendo com a translocação para o grão. Na cultivar mais produtiva houve acúmulo da massa dos ramos secos até a formação das vagens. Essa tendência foi verificada nas cultivares Negro Argel e A320, no regime de sequeiro (Tabela 1). Provavelmente, da última coleta de biomassa até a colheita de grãos, houve translocação de parte desta massa seca para as vagens e, em consequiência, menores reduções no rendimento de grãos, de $16 \%$ e $48 \%$, respectivamente (Tabela 2).

Em leguminosas, com a remobilização de assimilados acumulados nos ramos para as vagens há uma contribuição sensível para o rendimento de grãos, sobretudo sob deficiência hídrica (Subbarao et al., 1995). Tendo em vista que a translocação de carboidratos é menos sensível que a fotossíntese e a respiração (Kramer \& Boyer, 1995), a habilidade de uma cultivar quanto ao armazenamento e mobilização de reservas nos ramos, para posterior translocação aos grãos, pode ser uma característica de tolerância à seca (Blum, 1997).

$\mathrm{Na}$ cultivar Negro Argel, quando comparada com outras 11 cultivares de feijoeiro, verificou-se menor redução no rendimento, sob deficiência hídrica, sem efeitos do estresse hídrico no IAF e na duração da área foliar (Bascur et al., 1985). Nos resultados do presente trabalho, observou-se maior tolerância à seca na cultivar Negro Argel, com menor redução no rendimento e maior estabilidade no rendimento, em razão de: retardamento do acúmulo máximo de biomassa (Fig. 1), menor redução na biomassa de ramos nas últimas coletas e maior duração da área foliar (Tabela 1). Entretanto, verificou-se, nessa mesma cultivar, o menor rendimento sob irrigação (Tabela 2), característica comum a genótipos tolerantes à seca que, em geral, têm um menor potencial produtivo 
(Guimarães et al., 1996). Desta forma, é necessário identificar quais os atributos fisiológicos de parte aérea e de raiz que contribuem para a adaptação à seca (Blum, 1997), objetivando combiná-los seletivamente, nos materiais altamente produtivos e adaptados aos sistemas de produção atuais, pelo melhoramento genético (Subbarao et al., 1995).

Singh (1995) observou uma maior adaptação ao estresse hídrico nas raças de Phaseolus vulgaris nativas dos altiplanos áridos da Mesoamérica, e menor nas oriundas das regiões úmidas de baixa altitude da Mesoamérica, de onde se originaram a 'Negro Argel' e a maioria dos genótipos cultivados no Brasil. Atualmente, nas cultivares tolerantes à seca tem-se, como principal característica, o sistema radicular profundo, como na BAT 477 (White et al., 1990). Contudo, deve-se associar a essa característica, outras da parte aérea, que confiram tolerância à desidratação, como as características assinaladas neste trabalho na cultivar Negro Argel, e o controle estomático, verificado por diversos autores em outros genótipos (Pimentel et al., 1990; White et al., 1990).

\section{CONCLUSÕES}

1. Em condições de estresse hídrico, a biomassa da parte aérea e de seus componentes (folhas, ramos e vagens), o índice de área foliar e a taxa de crescimento da cultura das cultivares Carioca, Xodó e Negro Argel e da linhagem A320 são reduzidas.

2. Em relação à deficiência hídrica, a cultivar Carioca é sensível e a Negro Argel tolerante, considerando-se as reduções na acumulação de biomassa da parte aérea e rendimento de grãos, sob sequeiro.

3. A maior tolerância à seca da cultivar Negro Argel está associada à maior duração da área foliar e menor redução da biomassa de ramos ao final do ciclo, sob sequeiro.

\section{REFERÊNCIAS}

BASCUR, G.; OLIVA, M.A.; LAING, D. Termometria infrarroja en seleccion de genotipos de frijol (Phaseolus vulgaris L.) resistentes a sequia. II. Crecimiento y productividad. Turrialba, San José, v.35, p.49-53, 1985.
BLUM, A. Crop responses to drought and the interpretation of adaptation. In: BELHASSEN, E. (Ed.). Drought tolerance in higher plants: genetical, physiological, and molecular biological analysis. Dordrecht : Kluwer Academic, 1997. p.5770.

BRANDES, D.; MAESTRI, M.; VIEIRA, C.; GOMES, F.R. Efeitos da população de plantas e da época de plantio no crescimento do feijoeiro (Phaseolus vulgaris L.). II. Análise de crescimento. Experientiae, Viçosa, v.15, p.1-21, 1973.

CONSTABLE, G.A.; HEARN, A.B. Agronomic and physiological responses of soybean and sorghum crops to water deficit. I. Growth, development and yield. Australian Journal of Plant Physiology, Collingwood, v.5, p.159-167, 1978.

COSTA, R.C.L.; LOPES, N.F.; OLIVA, M.A. Crescimento, morfologia, partição de assimilados e produção de matéria seca em Phaseolus vulgaris L. submetido a três níveis de nitrogênio e dois regimes hídricos. Pesquisa Agropecuária Brasileira, Brasília, v.26, n.9, p.1453-1465, set. 1991.

DOORENBOS, J.; KASSAM, A.H. Yield response to water. Rome : FAO, 1979. 193p. (Irrigation and Drainage Paper, 33).

FAGERIA, N.K.; BALIGAR, V.C.; JONES, C.A. Common bean and cowpea. In: FAGERIA, N.K.; BALIGAR, V.C.; JONES, C.A. (Ed.). Growth and mineral nutrition of field crops. New York : M. Dekker, 1991. p.280-318.

GUIMARÃES, C.M. Relações hídricas. In: ARAUJO, R.S.; RAVA, C.A.; STONE, L.F.; ZIMMERMANN, M.J.O. (Ed.). Cultura do feijoeiro comum no Brasil. Piracicaba : Potafos, 1996. p.139-168.

GUIMARÃES, C.M.; STONE, L.F.; BRUNINI, O. Adaptação do feijoeiro (Phaseolus vulgaris L.) à seca. II. Produtividade e componentes agronômicos. Pesquisa Agropecuária Brasileira, Brasília, v.31, n.7, p.481-488, jul. 1996.

HUNT, R. Plant growth curves: the functional approach to plant growth analysis. London : E. Arnold, 1982. 248p.

KRAMER, P.J.; BOYER, J.S. Water relations of plants and soils. San Diego : Academic, 1995. 495p.

LOUREIRO, B.T.; MACHADO, P.B.; DENÍCULI, W.; FERREIRA, P.A. Efeito de diferentes lâminas de 
água sobre a produtividade do feijoeiro-comum (Phaseolus vulgaris L.). Revista Ceres, Viçosa, v.37, p.215-226, 1990.

MOREIRA, J.A.A.; SILVEIRA, P.M.; STONE, L.F. Irrigação. In: ARAÚJO, R.S.; RAVA, C.A.; STONE, L.F.; ZIMMERMANN, M.J.O. (Ed.). Cultura do feijoeiro comum no Brasil. Piracicaba : Potafos, 1996. p.465-522.

NETER, J.; WASSERMAN, W.; KUTNER, M.H. Applied linear statistical models. 3.ed. Burr Ridge : R. D. Irwin, 1990. 1181p.

NEUMANN, P.; CHAZEN, O.; BOGOSLAVSKY, L.; HARTUNG, W. Role of root derived ABA in regulating early leaf growth responses to water deficits. In: ALTMAN, A.; WAISEL, Y. (Ed.). Biology of root formation and development. New York : Plenum, 1997. p.147-154.

NORMAN, M.J.T.; PEARSON, C.J.; SEARLE, P.G.E. The ecology of tropical food crops. 2.ed. Cambridge, Grã-Bretanha : University Press, 1995. 430p.

PIMENTEL, C.; JACOB NETO, J.; GOI, S.R.; PESSANHA, G.G. Estresse hídrico em cultivares de Phaseolus vulgaris L. em simbiose com o Rhizobium leguminosarus biovar phaseoli. Turrialba, San José, v.40, p.520-526, 1990.

SINGH, S.P. Selection for water-stress tolerance in interracial populations of common bean. Crop Science, Madison, v.35, p.118-124, 1995.

STONE, L.F.; PORTES, T.A.; MOREIRA, J.A.A. Efeitos da tensão da água do solo sobre a produtividade e crescimento do feijoeiro. II. Crescimento. Pesquisa Agropecuária Brasileira, Brasília, v.23, n.5, p.503-510, maio 1988.

SUBBARAO, G.V.; JOHANSEN, A.C.; SLINKARD, R.C.; RAO, N.; SAXENA, N.P.; CHAUHAN, Y.S Strategies for improving drought resistance in grain legumes. Critical Reviews in Plant Sciences, Boca Raton, v.14, p.469-523, 1995.

WHITE, J.W.; CASTILLO, J.A.; EHLERINGER, J. Associations between productivity, root growth and carbon isotope discrimination in Phaseolus vulgaris under water deficit. Australian Journal of Plant Physiology, Collingwood, v.17, p.189-198, 1990. 